\title{
Physical Activity among Undergraduate University Students During the Pandemic Covid-19
}

Sara Avinna Mohd Hakim, Nur Khairunisa Abu Talip, Wan Firdaus Wan Chik, Ali Md Nadzalan, Zulkifli Ismail, Masshera Jamaludin, Mohd Rizal Md Razali

To Link this Article: http://dx.doi.org/10.6007/IJARBSS/v11-i10/11164

DOI:10.6007/IJARBSS/v11-i10/11164

Received: 12 August 2021, Revised: 04 September 2021, Accepted: 25 September 2021

Published Online: 11 October 2021

In-Text Citation: (Hakim et al., 2021)

To Cite this Article: Hakim, S. A. M., Talip, N. K. A., Chik, W. F. W., Nadzalan, A. M., Ismail, Z., Jamaludin, M., \& Razali, M. R. M. (2021). Physical Activity among Undergraduate University Students During the Pandemic Covid-19. International Journal of Academic Research in Business and Social Sciences, 11(10), 594-604.

\section{Copyright: (c) 2021 The Author(s)}

Published by Human Resource Management Academic Research Society (www.hrmars.com) This article is published under the Creative Commons Attribution (CC BY 4.0) license. Anyone may reproduce, distribute, translate and create derivative works of this article (for both commercial and non-commercial purposes), subject to full attribution to the original publication and authors. The full terms of this license may be seen at: http://creativecommons.org/licences/by/4.0/legalcode

$$
\text { Vol. 11, No. 10, 2021, Pg. } 594-604
$$




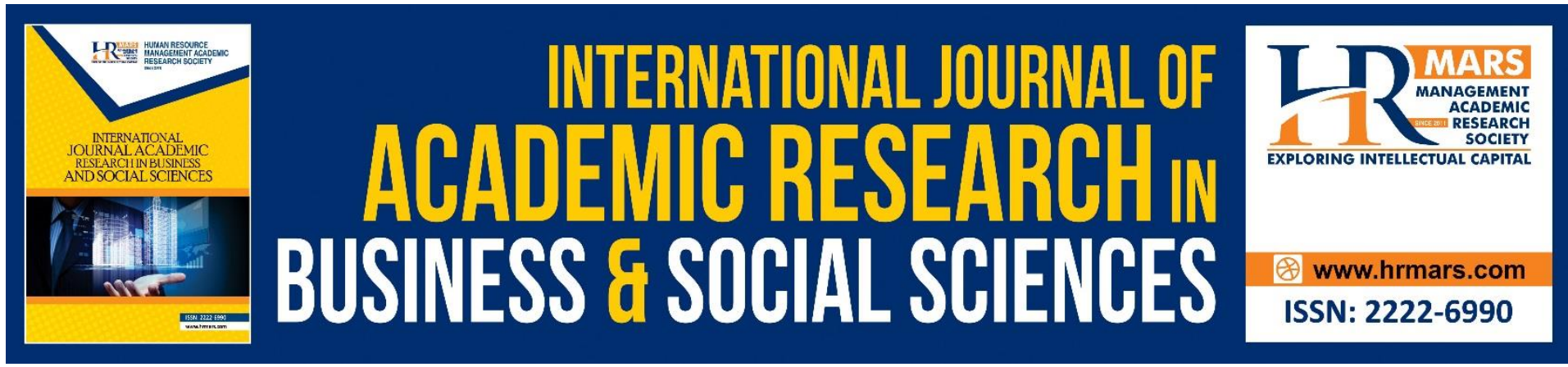

\title{
Physical Activity among Undergraduate University Students During the Pandemic Covid-19
}

\author{
Sara Avinna Mohd Hakim ${ }^{1}$, Nur Khairunisa Abu Talip ${ }^{1}$, Wan \\ Firdaus Wan Chik ${ }^{1}$, Ali Md Nadzalan², Zulkifli Ismail ${ }^{3}$, Masshera \\ Jamaludin ${ }^{3}$, Mohd Rizal Md Razali ${ }^{4}$ \\ ${ }^{1}$ Faculty of Sports Science and Recreation, Universiti Teknologi MARA, Sarawak Branch, \\ Malaysia, ${ }^{2}$ Faculty of Sports Science and Coaching, Universiti Pendidikan Sultan Idris, Perak, \\ Malaysia, ${ }^{3}$ Faculty of Sports Science and Recreation, Universiti Teknologi MARA, Perlis \\ Branch, Malaysia, ${ }^{4}$ Division of Research and Innovation, National Sports Institute of Malaysia \\ Email: nurkhairunisa331@uitm.edu.my
}

\begin{abstract}
Background: During coronavirus disease in 2019 (COVID-19) pandemic, the Malaysian government adopted Movement Control Order (MCO) to contain the spreading of COVID-19 including physical activity restrictions. The aims of this study were to measure the physical activity during pandemic COVID-19 among undergraduate university students, and to measure the difference between genders. Methods: A total sample of 400 full-time undergraduate university students from Universiti Teknologi MARA (UiTM), Sarawak Branch were recruited in this study. The International Physical Activity Questionnaire-Short Form (IPAQ-SF) was used to assess the physical activity. An electronic questionnaire was administered once to students during MCO Phase 3. The Independent Samples T-Test was used to identify the level of physical activity between genders. Results: During MCO the weekly total physical activity MET was $1734.80 \pm 1484.94$ min/week; with total mean for vigorous, moderate and walking MET of $640.80 \pm 897.48,500.75 \pm 728.652$ and $593.25 \pm 806.01$ $\mathrm{min} /$ week, respectively. The result of mean indicated that the total physical activity MET for undergraduate students during pandemic COVID-19 MCO (phase 3) was moderate-active ( $M=$ $1734.80 \mathrm{~min} /$ week). The findings shown that there was no significant difference $(p<0.05)$ between physical activity and gender (male and female) among undergraduate students during pandemic COVID-19. Conclusions: The physical activity level among undergraduate university students in Malaysia was found moderate-active during pandemic COVID-19 MCO phase 3.
\end{abstract}

Keywords: Exercise Behaviour, Coronavirus, 2019-Ncov, Lockdown, Movement Control Order, IPAQ-SF, Physical Inactivity, Exercise, Undergraduate

\section{Introduction}

In December 2019, the world was shaken by a potentially fatal virus that could cause death and its first identification in Wuhan City, Hubei Province, China. Coronavirus disease 2019 
(COVID-19), which is going to be a worldwide epidemic with high mortality and morbidity rate. COVID-19 is an emerging disease with an alarming rate in cases and death.

As of 30th April 2020, the widespread human-to-human transmission had resulted in 3,090,445 confirmed cases and 217,769 confirmed fatalities worldwide (World Health Organization, 2020). Specifically, Malaysia revealed its first COVID-19 cases on 25th January 2020 involving three tourists from Mainland China who had entered Malaysia via Johor from Singapore on 23rd January 2020 (Berita Harian Online, 2020). Prior to the data collection (September 30th, 2020) Malaysia had recorded a total of 11, 224 positive COVID-19 cases, including 136 deaths. Malaysia had almost 1,940,00 verified cases and 19,827 deaths as of this writing (September 11th, 2021), from the source from Ministry of Health Malaysia. Malaysia's government has imposed a multi-stage movement control order (MCO), compelling residents to remain at home and out only when absolutely necessary (Ministry of Health Malaysia, 2020).

As the COVID-19 pandemic spread throughout all countries, the authorities have implemented a series of mechanism, including the closure of schools and colleges, as well as travel restrictions, cultural and sporting events and social gatherings (Parnell et al., 2020). All of these actions may affect the mental and physical health of people, especially those familiarised to daily outdoor and/or physical activities. Typically, people spend more time sitting and watching devices during MCO, which may have an effect on their physical health, well-being, sleeping habits, and overall quality of life.

This is possibly due to the extremely limited opportunities during this time to perform physical activity outdoors since most individuals are required to stay at home and follow isolation procedures to avoid virus transmission. According to a survey conducted by Knight (2020), after the lockdown implemented, physical activity among adults has decreased by a quarter. A poll of 2,000 adults revealed that one-third had gained weight since coronavirus transmission limits were imposed, with an average gain of $6 \mathrm{lbs}$ (Knight, 2020). The average adult has reduced their daily physical activity from two hours a day to just an hour and 32 minutes during the lockdown prior to the restrictions. A survey conducted by the National Health and Morbidity Survey in Malaysia observed 50.1\% Malaysians have overweight issue; with the highest obesity (15.6\%) population in South East Asia (Berita Harian, 2020). Additionally, others asserted that MCO restricted physical activity, which resulted in weight gain. The issue of overweight or obese are usually linked to noncommunicable diseases (NCD) such as diabetes and heart attack; thus increasing the risk and decreasing the rate of survival if one is infected by COVID-19 (Berita Harian, 2020). Yorkshire Cancer Research (2020) found that, $68 \%$ of individuals were concerned about the effect that insufficient or no exercise on their health. It is also recommended that, by exercising at home, individuals should remain active.

A survey from the University College London (2020) conducted on the psychological and social experiences of people in the United Kingdom during the COVID-19 pandemic using an appbased and self-reported data, stated that 1 out 4 of people have not involved exercise or even gentle physical activity in the past 7 days; $85 \%$ of participants have not engaged in any moderate or strenuous exercise at all; and $40 \%$ of participants have not done any gentle exercise such as walking (Physiopedia, 2020). Meanwhile a study in Italy by Gallè et al. (2020) 
collected their data on the last three weeks of May 2020 focused on the sedentary behaviours and physical activity of Italian undergraduate students during lockdown the time of COVID19 showed the results testify an increase of time spent in sedentary activities and a consistent decrease in physical activity during home-confinement. Another study conducted in Spain between January and April 2020 among university students indicated physical activity reduction during confinement due to the COVID-19 pandemic (Romero-Blanco, RodríguezAlmagro, Onieva-Zafra, Parra-Fernández, Prado-Laguna \& Hernández-Martínez, 2020).

People must remain safe during periods of physical activity and lockdown or restricted and controlled movement. Any advantages of physical exercise could be directly applicable to the COVID-19 pandemic in view of the current situation worldwide. Physical exercise can boost immune function and minimize inflammation, so that the occurrence of infections can be decreased, improving common chronic conditions that increase the risk of severe COVID-19 diseases such as cardiovascular disease and diabetes (Physiopedia, 2020). Physical activity is also an excellent way to reduce symptoms of anxiety and depression through stress management, and helps regulate the levels of cortisol (Physiopedia, 2020). Stress and distress (such as during a pandemic) create imbalances in cortisol levels and may detrimental affect immune function and inflammation (Physiopedia, 2020).

Giustino, Parroco, Gennaro, Musumeci, Palma and Battaglia (2020) highlighted that physical inactivity causes over 5 million deaths worldwide. Besides, Rajappan, Selvaganapathy and Liew (2015) claimed that university students have been found to have poor physical activity patterns that contribute to poor body mass indexes. Wan Mohamed Radzi, Salarzadeh Jenatabadi, Alanzi, Mokhtar, Mamat and Abdullah (2019) studied obesity among Malaysian university students found that the prevalence of overweight and obesity among Malaysian university students is $21.2 \%$ and $16.3 \%$, respectively. Another previous study (Huda \& Ahmad, 2010) also found that about $12 \%$ university students is in the overweight category. Thus, this shows an upwards trend of obesity in Malaysia before the pandemic COVID-19. Perhaps now is the important time to study on physical activity to understand the issue and to prevent rocketing statistics of overweight and obesity in Malaysia due to physical inactivity during MCO. Hence, the present study focused on measuring physical activity during pandemic COVID-19 between October to December 2020 among undergraduate university students in Malaysia.

\section{Methodology}

\section{Period and Place of the Research}

The data collection was carried out from October to December 2020. At that time, the MCO phase 3 was implemented in Malaysia (Flanders Trade, 2021). During MCO phase 3, the standard of operating procedure is less strict and most of low to moderate risk social activities and outdoor physical activities were allowed to operate (Kementerian Kesihatan Malaysia, 2020). Researchers have obtained the written consent of all participants for voluntary participation at this study. The procedures were approved by the Research Committees from Universiti Teknologi MARA, Sarawak Branch.

\section{Sampling}

The population for this study was undergraduate students of Universiti Teknologi MARA (UiTM) Sarawak, which comprised of all three campuses which is Samarahan Campus, 
Samarahan 2 Campus, Mukah Campus. The study was conducted on a total of $400(n=400)$ undergraduate students with age range between 18 to 26 years. The sample size was calculate based on Krecjie and Morgan (1970) formula. Only current full-time undergraduate (male and female) university students were recruited to participate in this research.

\section{Procedure}

Researchers designed an electronic questionnaire for data collection purposes. Participation in the study was voluntary, all respondents may retract from the study at any time. This electronic questionnaire form begins with a brief description of the study, its purpose and the declarations of anonymity and confidentiality. The questionnaire comprised two sections which were Demographic Questionnaire to assess demographic factors (age, gender, education level) and International Physical Activity Questionnaire-Short Form (IPAQ-SF) to evaluate physical activity level. The study was conducted via an online survey form from October to December 2020.

The data was obtained using self-administered questionnaires of IPAQ-SF. The IPAQ-SF showed good reliability with all ICC $>0.80$ (Dinh, Andy, Thuy, Chung \& Dong, 2013). The IPAQSF includes 7 questions covering physical activity (PA) information for the previous 7 days.

\section{Scoring}

The collected data computed as the weekly physical activity level, expressed as energy expenditure in MET-minutes/week (MET-min/week) (http://www.ipaq.ki.se). The basal level of energy expenditure (expressed in MET) assigned to each type of physical activity (the corresponding metabolic equivalent task is: 3.3 for walking; 4.0 for moderate-intensity physical activities; 8.0 for vigorous-intensity physical activities, respectively) following the "Guidelines for Data Processing and Analysis of the International Physical Activity Questionnaire (IPAQ)-Short and Long Forms" (http://www.ipaq.ki.se). The estimated total weekly energy expenditure (i.e., the sum of walking, moderate-intensity physical activities and vigorous-intensity physical activities) in MET-min/week (Giustino et al., 2020).

As suggested by the IPAQ recommendations for scoring protocols, three levels of physical activity are proposed: (1) low physical activity (<600 MET-min/week); (2) moderate physical activity (>600 MET-min/week); (3) high active physical activity ( $\geq 3000 \mathrm{MET}-\mathrm{min} /$ week) (http://www.ipaq.ki.se; Giustino et al., 2020).

\section{Data Analysis}

The data collected analysed by using the SPSS version 22.0. The characteristic of physical activity was presented as frequency and mean \pm SD by category of physical activity MET. While, Independent Samples T-Test was employed to compare the physical activity between genders. Statistical significance was set at $p<.05$.

\section{Results and Discussions}

Table 1 shown the characteristics of the participants in the study. Table 2 shows frequency based on physical activity categories (low physical activity; moderate active; vigorous active physical activity) of the respondents. 
Table 1: Characteristics of the participants

\begin{tabular}{lll}
\hline & Categories & $\%(n)$ \\
\hline \multirow{2}{*}{ Age } & 18 to 20 years old & $53.3(213)$ \\
& 21 to 23 years old & $43.8(175)$ \\
\multirow{2}{*}{ Gender } & 24 to 26 years old & $3.0(12)$ \\
& Male & $50 \%(200)$ \\
\multirow{2}{*}{ Education Level } & Female & $50 \%(200)$ \\
& Diploma & $52.5 \%(210)$ \\
& Degree & $47.5 \%(190)$ \\
\hline
\end{tabular}

Table 2: Frequency and percentage of physical activity based on MET categories

\begin{tabular}{lll}
\hline Categories of physical activity & Frequency $(n)$ & Percentage (\%) \\
\hline Low & 82 & 20.5 \\
Moderate & 256 & 64 \\
Vigorous & 62 & 15.5 \\
\hline Total & 400 & 100 \\
\hline
\end{tabular}

Table 3 shows mean \pm SD for total physical activity MET, total vigorous, total moderate and total walking MET for both male and female students. The result of mean indicated that the the total physical activity MET for undergraduate students during pandemic COVID-19 MCO (phase 3$)$ is moderate-active $(M=1734.80)$.

Table 3: Interpretation of the categories of MET according with IPAQ-SF

\begin{tabular}{ll}
\hline IPAQ-SF & Total $(n=400)$ \\
\hline Total physical activity MET (min/week) & $1734.80 \pm 1484.94$ \\
Total Vigorous (min/week) & $640.80 \pm 897.48$ \\
Total Moderate (min/week) & $500.75 \pm 728.65$ \\
Total Walking (min/week) & $593.25 \pm 806.01$ \\
\hline
\end{tabular}

Levene's Test for Equality of Variances established the homogeneity of variance, showing that the significant value of the Levene test was greater than $p>.05$, thus the variable was not significantly different. An Independent Sample T-Test (in Table 4) was conducted shows no significant difference $(p>.05)$ between physical activity and gender. There was no significant difference of total physical activity MET ( $p=.672)$; total vigorous ( $p=.082)$; total moderate ( $p=$ $.968)$; total walking ( $p=.235$ ) between male and female undergraduate students during pandemic COVID-19. Therefore, physical activity during the COVID-19 pandemic were similar regardless of gender.

Table 4: Independent Sample T-Test between physical activity and gender

\begin{tabular}{lllllll}
\hline Categories & Gender & $\boldsymbol{n}$ & $\boldsymbol{M}$ & $\boldsymbol{S D}$ & $\boldsymbol{t}$ & $\boldsymbol{p}$ \\
\hline \multirow{2}{*}{ Total physical activity } & Male & 200 & 1766.29 & 1275.813 & .424 & .672 \\
& Female & 200 & 1703.31 & 1670.771 & & \\
\hline \multirow{2}{*}{ Total Vigorous } & Male & 200 & 718.8 & 793.32 & 1.743 & .082 \\
& Female & 200 & 562.8 & 986.61 & & \\
\hline \multirow{2}{*}{ Total Moderate } & Male & 200 & 502.2 & 569.58 & .040 & 0.968 \\
& Female & 200 & 499.3 & 860.3 & & \\
\hline \multirow{2}{*}{ Total Walking } & Male & 200 & 545.29 & 810.21 & -1.191 & .235 \\
& Female & 200 & 641.21 & 800.93 & & \\
\hline
\end{tabular}




\section{Discussion}

The present result shows that there was no significant difference of total physical activity MET $(p=.672)$; total vigorous MET ( $p=.082)$; total moderate MET $(p=.968)$; total walking MET ( $p=$ $.235)$ between male and female undergraduate students during pandemic COVID-19. The insignificant result was probably due to the similar conditions exposed on both genders. During MCO phase 3, standard of operating procedure is more loose. Thus, non-contact outdoor physical activities such as jogging, brisk walking and cycling were allowed.

Thus, results from the total physical activity MET shown that undergraduate students from UiTM, Sarawak Branch is categorised as moderate-active ( $M=1734.80 \mathrm{~min} /$ week) during pandemic COVID-19 MCO (phase 3) regardless of gender. Hammami, Harrabi, Mohr and Krustrup (2020) also claimed that during this time people usually have very limited opportunities to perform physical activity outdoors, since most individuals are forced to stay at home or follow isolation protocols to avoid virus transmission.

Previous parallel study conducted before pandemic COVID-19 in Malaysia among university students from Infrastructure University Kuala Lumpur, Malaysia suggested that the mean of total physical activity was $3988.50 \pm 6758.45 \mathrm{~min} /$ week (male with $5496.37 \mathrm{~min} /$ week; female with $3032.93 \mathrm{~min} /$ week (Mahgoub, Abu Saad \& Jamaluddin, 2016). Previous study was also conducted in Greece in year 2015 studied on the level of physical activity of university students showed the mean total MET of $5343.92 \pm 2314.02$ (male students with 5993.69 min/week; female student with 4303.285 min/week) (Fagaras, Radub \& Vanvuc, 2015). The difference of physical activity MET among undergraduate university is very concerning; while the present study data was limited to only during the MCO. Thus, future study is needed to measure the physical activity MET using similar instrumentations (IPAQ-SF) during or after the pandemic is resolved.

According to Giustino et al (2020), which studied about physical activity levels and related energy expenditure during COVID-19 quarantine among active population in Sicilian, Italy; found that the lockdown has resulted in a change in the behaviours of the Italian people, including a change in the practice of physical activity. This study also showed that during the COVID-19 quarantine, $77 \%$ of the total 615 participants experienced a drop in total weekly expenditure. According to Sañudo, Fennell and Sánchez-Oliver (2020), due to the COVID-19 lockdown, the habits of the individual may have changed and found that during the containment there was a total increase in smartphone use compared to prior to the containment. Study from Gallè et al (2020) further explained that the primary form of physical activity in Italy decreased during the lockdown was walking. This could be explained by the limitation of outdoor movement. In fact, grocery shopping is the only activity permitted during the lockdown. Gallè et al (2020) also found that the sedentary activity was highly increased on using their electronic devices (an increase of $52.4 \mathrm{~min} /$ day), while walking was the physical activity component which had the greatest decrease (reduced by 365.5 $\mathrm{min}$ (week). In addition, majority of the students had online classes during the lockdown, instead of face-to-face classes. Thus, it meant that the face-to-face requirements such as to walk to scheduled class; printing their assignments; attending physical meeting has inevitably contributed to their walking time being reduced. Hence, this explained the moderate physical activity $(M=1734.80)$ (based on IPAQ) observed among the undergraduate students in Malaysia during pandemic COVID-19 (October to December 2020). 
A study done by Romero-Blanco et al (2020) discovered that motivation appeared to impact whether university students participate in physical activity significantly. Male and female exercise motivation differs from one another and their surrounding atmosphere. Male motivation to exercise is primarily influenced by external factors such as competition and social recognition. In contrast, female motivation is predominantly driven by selfconsciousness about weight. Also, physical activity decreased due to anxiety and boredom, while screen time increased because of the lockdown period. According to a study conducted by Rodríguez-Larrad et al (2021), university students reduced the amount of time in moderate and vigorous physical activity but increased their participation in HIIT, mind-body activities, maintaining strength exercise, and widely used social media as a support motivation for physical exercise. Because of social media's undeniable positive impact, it may be beneficial to encourage students to engage in more physical activity in the future.

The results contribute some preliminary findings to the current issue, which is physical activity level during the pandemic COVID-19. Moreover, the result focuses explicitly on university students in Malaysia. The result in this study highlights the need for physical activity promotion interventions targeted at the examined population. During a lockdown, the online method may be a helpful resource to transmit health promotion messages, and it has been used by international and national institutions (World Health Organization, 2020). The results are also valuable to publish in the National Health and Morbidity Survey report by the Institute for Public Health, Ministry of Health, Malaysia. The result is believed to be a point of reference for future study to investigate physical activity level during post COVID-19.

\section{Conclusion}

In conclusion, the obtained results of the presented study indicate that the full-time undergraduate students from UiTM Sarawak Branch scored a moderate physical activity level during pandemic COVID-19. There is also an insignificant difference in total physical activity $M E T$; vigorous MET; moderate MET; and walking MET between genders.

Based on previous similar research, there is a possibility of a significant decrease of total physical activity MET from high-active physical activity (Mahgoub, et al., 2016) to moderateactive physical activity (observed in the present study). Muniz-Pardos et al (2020) proposed that the impact of the COVID-19 related reduction in physical activity was worrying considering the already insufficient physical activity levels observed prior to the COVID-19 pandemic, with approximately $27.5 \%$ of adults not meeting the WHO recommendations for physical activity in 2016. Thus, the best way to overcome these problems is through simple home-based exercises such as bodyweight training to reduce sedentary behaviour. Promoting home-based activities that increase mobility, such as gardening, mild housework and flavourful meal preparation, can be used to break sedentary behaviour, increase physical activity and muscular strength levels, and boost mood in older people, thereby promoting health and well-being (Muniz-Pardos et al., 2020).

In a nutshell, being physically active not only important for physical and mental health; it will as well will strengthening immune functions and reducing the severity of a possible infection, particularly given recent evidence that obesity is an additional risk factor for COVID-19 (Muniz-Pardos et al., 2020). Let fitness help! 


\section{Recommendation for Future Studies}

Future studies is recommended to measure the physical activity levels at different timeframe, such as at different MCO phases and/or COVID-19 had been resolved. Future studies may also incorporate the use of pedometer, and obtain anthropometrics measurement such as body mass index alongside the use of IPAQ. Last but not least, the effectiveness of coping strategy to combat physical inactivity shall be further studied, for example virtual group exercise programme and/or virtual marathon programme.

\section{References}

Berita Harian Online. (2020). Kronologi COVID-19 di Malaysia. https://www.bharian.com.my/berita/nasional/2020/03/666122/kronologi-covid-19di-malaysia.

Berita Harian Online. (2020). Trend Obesiti di Malaysia 'Menggerunkan'. https://www.bharian.com.my/wanita/sihat/2020/06/702978/trend-obesiti-dimalaysia-menggerunkan

Dinh T. V., Andy L. H., Thuy T. B., Chung N. T., Dong H. V. (2013). Reliability and validity of the International Physical Activity Questionnaire-Short Form for older adults in Vietnam. Health Promotion Journal of Australia 24, 126-131. https://doi.org/10.1071/HE13012.

Fagaras, S. P., Radub, L. E., \& Vanvuc, G. (2015). The level of physical activity of University students. Procedia-Social and Behavioral Sciences, 197, 1454-1457.

Flanders Trade. (2021). CORONA VIRUS- The Situation in Malaysia. https://www.flandersinvestmentandtrade.com/export/nieuws/coronavirus--situation-malaysia.

Gallè, F., Sabella, E. A., Ferracuti, S., De Giglio, O., Caggiano, G., Protano, C., Valeriani, F., Parisi, E. A., Valerio, G., Liguori, G., Montagna, M. T., Romano Spica, V., Da Molin, G., Orsi, G. B., \& Napoli, C. (2020). Sedentary behaviors and physical activity of Italian undergraduate students during lockdown at the time of CoViD-19 pandemic. International Journal of Environmental Research and Public Health, 17(17), 6171. https://doi.org/10.3390/ijerph17176171

Giustino, V., Parroco, A. M., Gennaro, A., Musumeci, G., Palma, A., \& Battaglia, G. (2020). Physical activity levels and related energy expenditure during COVID-19 quarantine among the Sicilian active population: A cross-sectional online survey study. Sustainability, 12(11), 4356. https://doi.org/10.3390/su12114356

Hammami, A., Harrabi, B., Mohr, M., \& Krustrup, P. (2020). Physical activity and coronavirus disease 2019 (COVID-19): Specific recommendations for home-based physical training. Managing Sport and Leisure, 1-6. https://doi.org/10.1080/23750472.2020.1757494

Huda, N., \& Ahmad, R. (2010). Preliminary survey on nutritional status among university students at Malaysia. Pakistan Journal of Nutrition, 9(2), 125-127.

Institute for Public Health (IPH). (2015). National Health and Morbidity Survey 2015 (NHMS 2015). Vol. II: Non-Communicable Diseases, Risk Factors \& Other Health Problems; 2015.

International Physical Activity Questionnaire (IPAQ)-Short and Long Forms (2020). http://www.ipaq.ki.se.

Kementerian Kesihatan Malaysia. (2021). FAQ dan SOP. https://covid19.moh.gov.my/faqsop/sop-pkp-pemulihan. 
Knight, R. (2020). Adult physical activity falls by a quarter since lockdown. The Independent. Independent. https://www.independent.co.uk/life-style/health-andfamilies/coronavirus-lockdown-physical-activity-reduced-exercise-weighta9505411.html

Krejcie, R. V., \& Morgan, D. W. (1970). Determining sample size for research activities. Educational and psychological measurement, 30(3), 607-610.

Mahgoub, S. K., Abu Saad, H., Jamaluddin, R. (2016). Factors Associated With Body Weight Status among Students in Infrastructure University Kuala Lumpur (IUKL), Kuala Lumpur, Malaysia. Journal of Medical Science and Clinical Research 4(2), 9240-9251.

Ministry of Health Malaysia [kementeriankesihatanmalaysia]. (2020). Terkini \#COVID19Malaysia 30 Sept 2020. [Photograph]. Instagram.

https://www.instagram.com/p/CFwprcZgh6y/?utm_medium=copy_link.

Muniz-Pardos, B., Shurlock, J., Debruyne, A., Steinacker, J. M., Börjesson, M., Wolfarth, B., ... \& Pitsiladis, Y. P. (2020). Collateral health issues derived from the Covid-19 pandemic. Sports Medicine-Open, 6(1), 1-4.

ONAPS. (2020). Pandémie de COVID-19 : Mesures barrières renforcées pendant Le confinement et en phase de sortie de confinement. Bulletin de l'Académie Nationale de Médecine, 204(7), 654-655. https://doi.org/10.1016/j.banm.2020.05.033

Parnell, D., Widdop, P., Bond, A., \& Wilson, R. (2020). COVID-19, networks and sport. Managing Sport and Leisure, 1-7. https://doi.org/10.1080/23750472.2020.1750100 Physiopedia. Physical activity and COVID-19. https://physiopedia.com/Physical_Activity_and_COVID-19

Rajappan, R., Selvaganapathy, K., \& Liew, L. (2015). Physical activity level among university students: A cross sectional survey. International Journal of Physiotherapy and Research, 3(6), 1336-1343. https://doi.org/10.16965/ijpr.2015.202

Rodríguez-Larrad, A., Mañas, A., Labayen, I., González-Gross, M., Espin, A., Aznar, S., SerranoSánchez, J. A., Vera-Garcia, F. J., González-Lamuño, D., \& Ara, I. (2021). Impact of COVID19 confinement on physical activity and sedentary behaviour in Spanish University Students: role of gender. International Journal of Environmental Research and Public Health, 18(2), 369.

Romero-Blanco, C., Rodríguez-Almagro, J., Onieva-Zafra, M. D., Parra-Fernández, M. L., PradoLaguna, M. D., \& Hernández-Martínez, A. (2020). Physical activity and sedentary lifestyle in University students: Changes during confinement due to the COVID-19 pandemic. International Journal of Environmental Research and Public Health, 17(18), 6567. https://doi.org/10.3390/ijerph17186567.

Sañudo, B., Fennell, C., \& Sánchez-Oliver, A. J. (2020). Objectively-assessed physical activity, sedentary behaviour, smartphone use, and sleep patterns pre-and during-COVID-19 quarantine in young adults from Spain. Sustainability, 12(15), 5890.

University College London. (2020). More people are worried about food, friends and family than getting ill from COVID-

19. https://www.ucl.ac.uk/news/2020/apr/more-people-are-worried-about-foodfriends-and-family-getting-ill-covid-19-0

World Health Organization. (2019). Physical activity. WHO | World Health Organization. https://www.who.int/health-topics/physical-activity\#tab=tab_1

World Health Organization. (2020). Coronavirus disease 2019 (COVID-19) Situation Report. WHO | World Health Organization. https://www.who.int/docs/defaultsource/coronaviruse/situation-reports/20200430-sitrep-101-covid-19.pdf 
INTERNATIONAL JOURNAL OF ACADEMIC RESEARCH IN BUSINESS AND SOCIAL SCIENCES

Vol. 11, No. 10, 2021, E-ISSN: $2222-6990$ @ 2021 HRMARS

Yorkshire Cancer Research. (2020). Physical activity among adults in Yorkshire has fallen by a quarter since the lockdown. https://yorkshirecancerresearch.org.uk/news/physicalactivity-among-adults-in-yorkshire-has-fallen-by-a-quarter. 